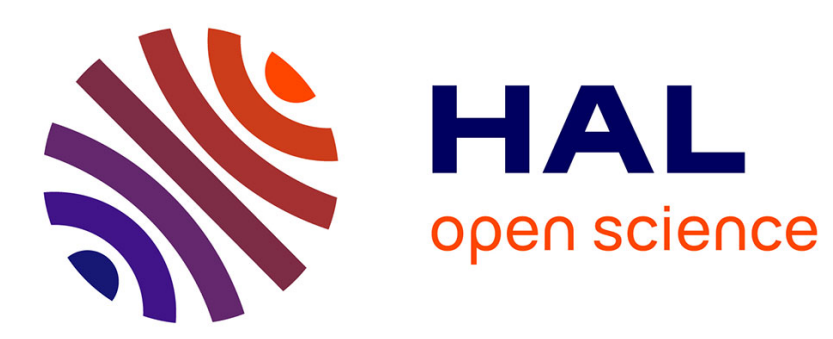

\title{
Dislocation mobility and crack tip plasticity at the ductile-brittle transition
}

\author{
P.B. Hirsch, S.G. Roberts, J. Samuels
}

\section{To cite this version:}

P.B. Hirsch, S.G. Roberts, J. Samuels. Dislocation mobility and crack tip plasticity at the ductile-brittle transition. Revue de Physique Appliquée, 1988, 23 (4), pp.409-418. 10.1051/rphysap:01988002304040900 . jpa-00245789

\section{HAL Id: jpa-00245789 https://hal.science/jpa-00245789}

Submitted on 1 Jan 1988

HAL is a multi-disciplinary open access archive for the deposit and dissemination of scientific research documents, whether they are published or not. The documents may come from teaching and research institutions in France or abroad, or from public or private research centers.
L'archive ouverte pluridisciplinaire HAL, est destinée au dépôt et à la diffusion de documents scientifiques de niveau recherche, publiés ou non, émanant des établissements d'enseignement et de recherche français ou étrangers, des laboratoires publics ou privés. 


\title{
Dislocation mobility and crack tip plasticity at the ductile-brittle transition
}

\author{
P.B. Hirsch, S.G. Roberts and J. Samuels \\ Department of Metallurgy and Science of Materials, \\ University of Oxford, Parks Road, Oxford OX1 3PH, G.B.
}

(Reçu le 26 mai 1987, accepté le 11 août 1987)

\begin{abstract}
RÉSUMÉ.- Nous présentons une revue des idées récemment développées sur les mécanismes contrôlant les stades initiaux de la déformation plastique au niveau des fissures dans des matériaux intrinsèquement fragiles au voisinage de la transition ductile-fragile. Nous rendons compte d'expériences nouvelles dans des échantillons préalablement fissurés de silicium, celles-ci confirment de précédents travaux sur le contrôle par la vitesse des dislocations de la transition ductile-fragile. Nous proposons un modèle dans lequel, à la transition, un nombre fini de sources en tête de fissures émettent des dislocations suffisamment vite pour protéger les parties les plus vulnérables de la fissure, réduisant ainsi, loin des sources, le facteur d'intensité des contraintes locales à des valeurs inférieures à $K_{1 c}$ pour des facteurs d'intensité des contraintes appliquées $K$ supérieurs à $K_{1 c}$. La simulation de la dynamique des dislocations engendrées par l'extrémité de la fissure, dans le mode III de charge, suggère que si les sources deviennent actives pour des valeurs dé $\mathrm{K}$ proches des $\mathrm{K}_{i c}$, il se produit une transition brutale. Nous proposons que les sources se créent lorsque des dislocations existantes sont attirées à l'extrémité de la fissure où elles rendent efficaces des sources auparavant écrantées. Ce modèle explique que la dépendance en vitesse de déformation de $\mathrm{T}_{\mathrm{C}}$ soit déterminée par l'énergie d'activation de la vitesse des dislocations, il prédit aussi que $\mathrm{T}_{C}$ dépend de la densité des dislocations. Nous tirons des conclusions générales sur les facteurs contrôlant la résistance d'échantillons préfissurés de matériaux intrinséquement fragiles ì la transition ductile-fragile.
\end{abstract}

Abstract. - Recent ideas on the mechanisms controlling the initial stages of plastic flow at cracks in intrinsically brittle materials, at the ductile-brittle transition, are reviewed. New experiments on precracked specimens of $\mathrm{Si}$ are reported, which confirm earlier work that the ductile-brittle transition is controlled by dislocation velocity. A model has been developed in which at the ductile-brittle transition dislocations from a discrete number of sources at the crack tip are emitted sufficiently rapidly to shield the most vulnerable parts of the crack, furthest away from the sources, at a rate such that the local stress intensity factor remains below $K_{1}$ for values of the applied stress intensity factor $K$ above $\mathrm{K}_{1 \mathrm{c}}$. Computer modelling of the dynamics of dislocation generation from the crack tip, in mode III loading, suggests that a sharp transition is obtained if crack tip source activity begins at values of $\mathrm{K}$ close to $\mathrm{K}_{1 \mathrm{c}}$. It is suggested that crack tip sources can be formed when existing dislocations are attracted to the crack tip, where they transform into efficient shielding sources. The model explains the observed strain rate dependence of the transition temperature $\left(T_{c}\right)$ on the activation energy controlling dislocation velocity, and predicts a dependence of $\mathrm{T}_{\mathrm{c}}$ on dislocation density. The predictions of the model are in good agreement with observed values of $\mathrm{T}_{c}$ for $\mathrm{Si}$. General conclusions are drawn about the factors which control yielding in precracked specimens of intrinsically brittle materials at . the ductile-brittle transition.

\section{Introduction}

During the last few years there has been an upsurge in interest in the phenomena which control whether crystalline solids containing cracks deform in a brittle or ductile manner. In earlier work [1] Kelly, Cottrell and Tyson argued that a material will be brittle or ductile according to whether the ratio of the maximum tensile stress to the maximum shear stress close to a crack tip is greater or 
smaller than the ratio of the ideal tensile strength to the ideal shear strength for that particular material. This approach predicts that f.c.c. metals should be intrinsically ductile, and covalently bonded solids such as diamond should be brittle, while the predicted behaviour of b.c.c. metals is rather uncertain.

Rice and Thomson [2] refined this approach by considering the nucleation of dislocations at crack tips in the presence of stress. A dislocation line parallel to the line of the crack tip, emitted under the action of the crack tip stress, is attracted back to the crack by the elastic image stress, and the stress arising from the formation of a ledge. Fig. 1 shows schematically the force on the disloca-

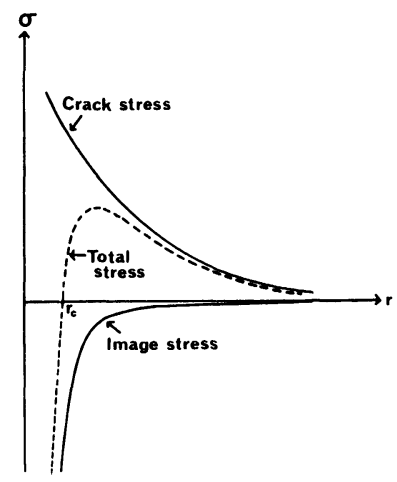

Fig.1: Force on a dislocation as a function of distance from the crack tip. If the dislocation core radius exceeds $r_{c}$ dislocations will be spontaneously emitted; if it is less than $r_{c}$ an energy barrier has to be overcome before emission can occur.

tions as a function of distance from the crack tip. If the total force on the dislocations at a distance equal to the dislocation core radius repels the dislocation from the crack, spontaneous emission of dislocations occurs and the material is ductile; if the force attracts the dislocation back into the crack the material is intrinsically brittle, but dislocation emission can occur by thermal activation over an energy barrier. This approach predicts that f.c.c. metals are generally ductile, and that a number of materials including $\mathrm{Si}$ and $\mathrm{Ge}$ and some b.c.c. metals are intrinsically brittle. Rice and Thomson also estimated the activation energies for the formation of stable dislocation loops, and the values for many brittle materials were found to be very high (.e.g. for Si, $\sim 111 \mathrm{ev}$ ). Haasen [3] suggested that the activation energy for $\mathrm{Si}$ would be much smaller ( $0.5 \mathrm{ev}$ ) if partials rather than whole dislocations were nucleated, and calculations due to Lin, Chuang and Thomson [4] confirmed Haasen's estimates. Argon [5] has pointed out that in the calculations of critical loop size the displacement (i.e. Burgers vector), should be chosen as a variable, and that consequently the activation energies would be found to be much lower than those predicted on the Rice-Thomson analysis. It is of course well known that many of the intrinsically brittle solids have ductile-brittle transitions (DBT) at temperatures much lower than would be inferred from the very high estimates of activation energies made by Rice and Thomson. Thus, for example, it was shown by St. John [6] that the DBT in $\mathrm{Si}$ is controlled by an activation energy of $\sim 1.9 \mathrm{ev}$, which is the activation energy for dislocation velocity. These experimental observations could in principle be consistent with thermally activated nucleations at the crack tip, provided the activation energy for loop nucleation is less than this value.

Various alternatives or modifications of the Rice-Thomson analysis have been suggested (e.g. Ohr [7], Burns and Webb [8]); for review see Thomson [4]; but none of these treatments predicts the temperature $\mathrm{T}_{c}$ at which the DBT occurs. Argon [5] has developed a theory in which $\mathrm{T}_{c}$ is related to the condition at which dislocation trails in the wake of a moving crack form so fast that the blunting and shielding from these dislocations reduces the local stress at the crack tip to a value below that required for continued propagation of the cleavage crack. The transition temperatures predicted are much higher than experimentally observed, and this is attributed to the unrealistically high values of activation energy.

Rice-Thomson's condition for ductility implies that dislocation nucleation at the crack tip occurs at values of local stress intensity $(K)$ less than that for cleavage. The experiments of $\mathrm{Ohr}$ and coworkers [7] on crack propagation in thin foils in the electron microscope, provide direct evidence for the nucleation and emission of dislocations at crack tips in a number of f.c.c. and b.c.c. metals, mainly under mode III and mode II deformation conditions. On the other hand, it is well known that $T_{c}$ can be changed by altering the micro-structure. For example, $T_{c}$ in steels is raised by neutron irradiation, and b.c.c. metals can be ductilised by prior plastic working. Ashby and Embury [9] have suggested a model in which $T_{c}$ decreases when the dislocation density in the material is sufficiently high so that there will always be dislocations close enough to a moving crack to be able to glide at the same velocity and perform plastic work. Lin and Thomson's [10] interpretation of the effect of dislocation density on $T_{c}$ is that movement of existing glide dislocations to the crack tip can promote emission, and that this reduces $T_{c}$. The effect of bulk microstructure in b.c.c. metals on $T_{c}$ is of course more general; on the whole changes in microstructure which raise the yield stress, e.g. neutron irradiation, will tend to increase $T_{c}$. The important common factor controlling yield stress and $\mathrm{T}_{\mathrm{c}}$ is dislocation velocity. Obstacles which impede dislocation motion and reduce average velocity raise the yield stress, and, by reducing plastic work around the crack and possibly making emission more difficult, lead to an increase in $T_{c}$.

The question remains whether, in relatively dislocation-free bulk materials, $T_{c}$ is controlled by homogeneous nucleation at the crack tip, or by existing or potential dislocation sources. In the case of $\mathrm{Si}$, where St. John [6] showed that $\mathrm{T}_{c}$ is controlled by dislocation velocity, Haasen [3], following an earlier treatment by St. John [6], developed a theory in which it is assumed that dislocation nucleation occurs relatively easily at the crack tip, but that the rate of blunting is controlled by the rate at which dislocations can move away from the crack tip, i.e. by the dislocation velocity. $T_{c}$ occurs when crack blunting is so fast that the critical stress for fracture at the crack tip is not reached even though the applied $\mathrm{K}$ 
rises above $K_{1 c}$. This model predicts that the strain-rate dependence of $T_{c}$ is controlled by the activation energy for dislocation motion.

In this paper we report the results of new experiments on $\mathrm{T}_{c}$ in $\mathrm{Si}$, aimed at elucidating some of the fundamental processes which control $T_{c}$. Both mechanical tests and studies of dislocation activity by etching fracture faces were carried out. In order to test further St. John's result that the strain rate dependence $(\dot{K})$ of $T_{c}$ is controlled by the activation energy for dislocation velocity, experiments were carried out on $n$ and $p$ type as well as intrinsic silicon. In semiconductors the dislocation velocity $\mathrm{v}$ is given by

$$
\mathrm{v}=\mathrm{A} \boldsymbol{\tau}^{\mathrm{m}} \exp -\mathrm{U} / \mathrm{kT}=\boldsymbol{\tau}^{\mathrm{n}} \mathrm{v}_{\mathrm{o}}
$$

where $m$ is approximately constant $\left(m^{\sim} 1-2\right)$, $U$ is the activation energy, which depends on doping (e.g. George and Champier [11]) and $v_{0}$ is the temperature dependent part of the velocity. The activation energy is generally thought to be controlled by the generation and movement of double kinks, and the doping effect is an electronic effect. The subject has been reviewed recently by Hirsch [12].

\section{Experiments on $\mathrm{Si}$}

Fracture experiments were carried out using 4-point bend tests on bars of float zone Si containing surface 'thumbnail' cracks introduced by hardness indentation. Two sizes of crack were used, with radii $13 \mu, 37 \mu$ respectively. Fig.2 shows the geometry. The specimens all contained a small plastic zone just below the indentation and were annealed at $800^{\circ} \mathrm{C}$ to remove the internal stress.

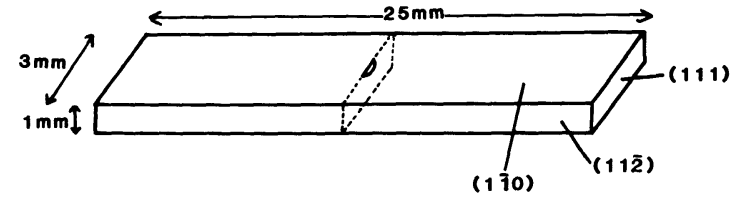

Fig.2: Geometry of precracked specimens of Si for 4-point bend tests.

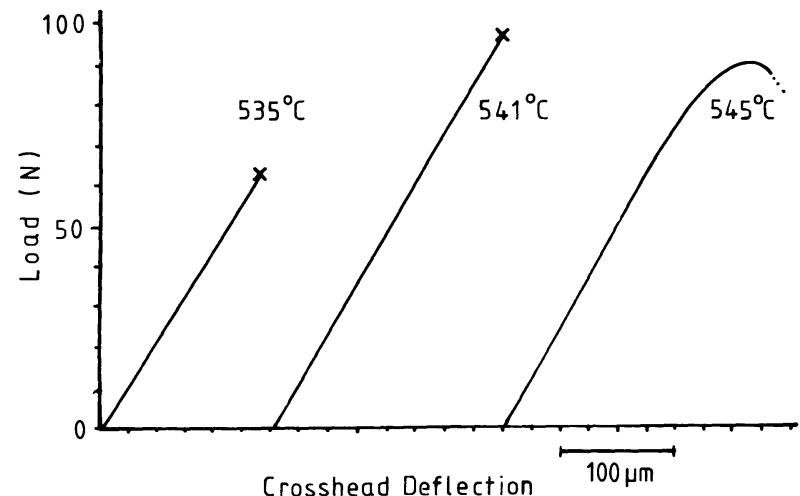

Fig.3: Load-deflection curves below the transition $\left(535^{\circ} \mathrm{C}\right)$, at the transition temperature $\left(541^{\circ} \mathrm{C}\right)$, and above the transition $\left(545^{\circ} \mathrm{C}\right)$, for intrinsic $\mathrm{Si}$.

Fig. 3 shows typical load-deflection curves below $\mathrm{T}_{\mathrm{c}}$ $\left(535^{\circ} \mathrm{C}\right)$, at $\mathrm{T}_{\mathrm{c}}\left(541^{\circ} \mathrm{C}\right)$ and above $\mathrm{T}_{\mathrm{c}}\left(545^{\circ} \mathrm{C}\right)$. The failure is brittle below and at $T_{c}$, but above $T_{c}$ the whole specimen deforms plastically, i.e. the maximum load is controlled by the yield stress. Fig. 4 shows the fracture stress below $T_{c}$ and the yield stress above $\mathrm{T}_{\mathrm{c}}$ for intrinsic Si. The transition is found to be very sharp, to within a few degrees. Fig.5 shows the transition temperature for different strain rates, for $n$-type Si. There is a pronounced strain-rate dependence, as already reported by St. John [6] and Brede [13].

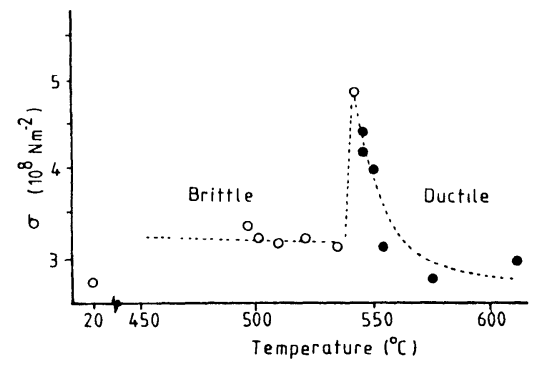

Fig.4: Fracture stress below $\mathrm{T}_{c}$ and yield stress above $\mathrm{T}_{\mathrm{c}}$ for intrinsic $\mathrm{Si}$.

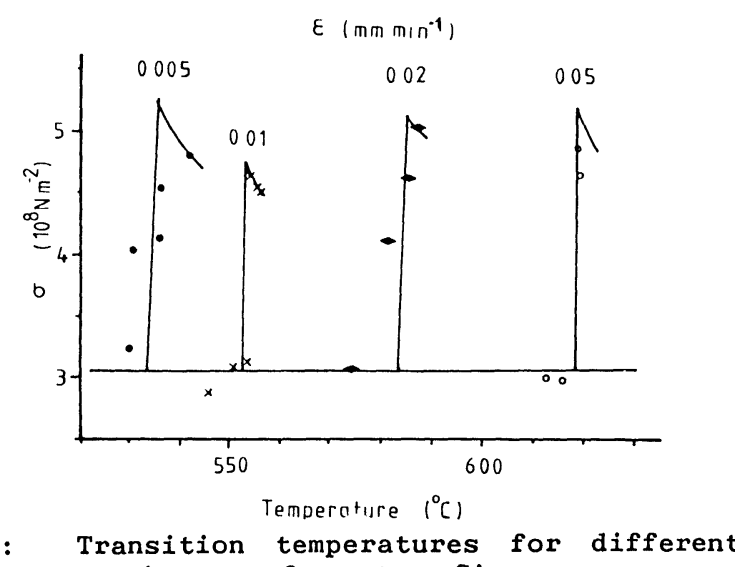
strain rates for $n$-type $\mathrm{Si}$.

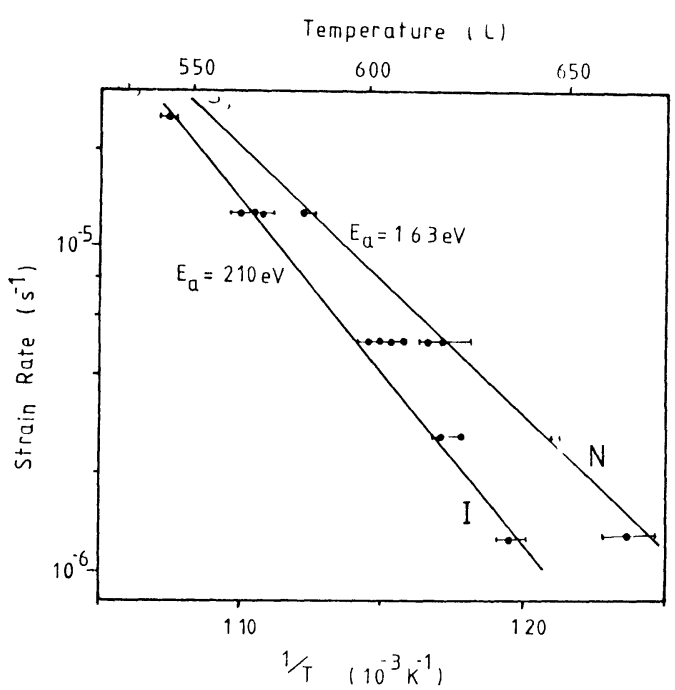

Fig.6: Plot of $\log$ (strain-rate) versus $T_{c}^{-1}$ for intrinsic and n-type $\mathrm{Si}$, for specimens with the small crack size. 
Fig. 6 is a plot of Log (strain-rate) against $\mathrm{T}^{-1}$ for intrinsic and n-type $\mathrm{Si}$. All the data were obtained for the small crack size $(13 \mu)$. For both types of $\mathrm{Si}$ the relationship

$$
\log \dot{\mathrm{K}}=\mathrm{B}-\mathrm{U} / \mathbf{k} \mathrm{T}_{\mathrm{c}}
$$

is obeyed. Table 1 lists the values of activation energy.

\section{$\underline{\text { Table } 1}$}

\section{U ev:-}

Intrinsic $\left(2 \times 10^{13} \mathrm{Pcm}^{-3}\right)$

$$
\begin{gathered}
\text { n-type } \\
\left(2 \times 10^{18} \mathrm{Pcm}^{-3}\right)
\end{gathered}
$$

Oxford

$$
2.1
$$$$
1.6
$$

St. John

$$
1.9
$$$$
-
$$

Dislocation Velocity 2.2

(George and Champier[11])

These results confirm St. John's conclusion that $T_{c}$ is controlled by the activation energy for dislocation velocity, i.e. that

$$
\text { K } \alpha v_{0}
$$

Fig.7 shows the data of Fig.6, one point for p-type material $\left(1.2 \times 10^{17} \mathrm{Bcm}^{-3}\right)$, and one point for intrinsic material but from specimens containing the larger cracks (radius $37 \mu$ ). St. John's data for intrinsic material are also shown. The latter were obtained using a different geometry, namely a modified compact tension specimen in the shape of a wedge; for this geometry $\mathrm{K}$ remains approximately constant if the crack advances, i.e. $K$ is approximately independent of crack length.

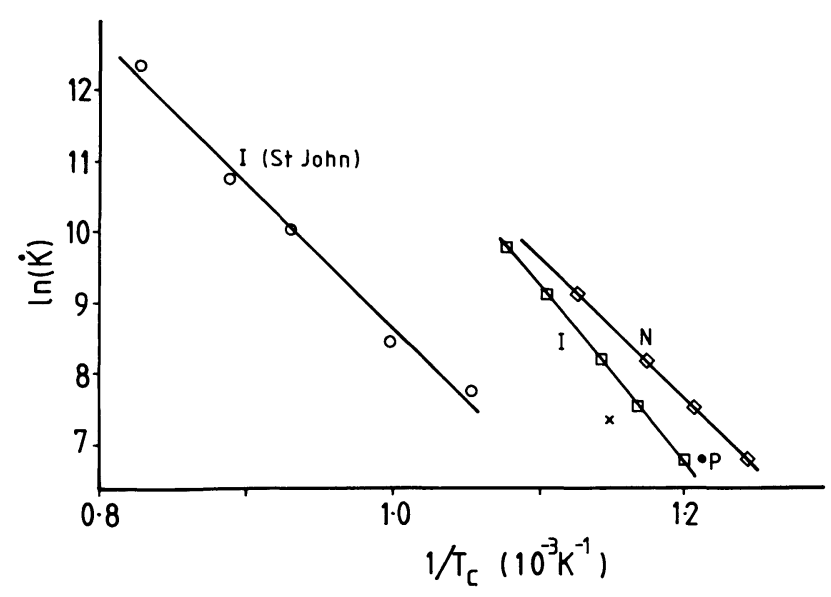

Fig. 7: Plots of $\log \dot{\mathrm{K}}$ versus $\mathrm{T}_{\mathrm{c}}^{-1}$ for intrinsic (I) and $n$-type material $(\mathrm{N})$, and point $P$ is for p-type material, all for specimens with the small crack size; point $X$ is for intrinsic material specimens with the larger crack size. For comparison St. John's results for intrinsic material are shown.
These results show:

(a) a shift of $\mathrm{T}_{\mathrm{c}}$ for $\mathrm{p}$ type material relative to that for intrinsic material; this shift is in accord with expectation from dislocation velocity measurements;

(b) there is a substantial shift in $T_{c}$ to higher temperature for larger crack sizes for the same material;

(c) the values of $T_{c}$ in the oxford experiments are $\sim 100^{\circ} \mathrm{C}$ lower than those in St. John's experiments for the same material and comparable strain-rates.

The fracture faces were etched to reveal dislocations. Specimens fractured below $T_{c}$, even within a few degrees of $T_{c}$, showed only very few dislocation etch pits in the crack region. Specimens which failed at $T_{c}$, or others which were unloaded at $T_{c}$ at values of $K$ substantially greater than $K_{1 c}$, and then fractured at room temperature showed etch pits in the original crack profile and in trains emanating from the crack. Fig. $8 \mathrm{a}$ is an optical micrograph of a specimen which failed at $\mathrm{T}_{\mathrm{c}}$ at $\mathrm{K}=1.6 \mathrm{M} \mathrm{Pa} \mathrm{m} \mathrm{m}^{1 / 2}$. Fig. $8 \mathrm{~b}$ reproduces the pattern of etch pits in Fig. $8 \mathrm{a}$ outside the original crack profile. Specimens deformed at $T_{c}$ and unloaded below $\mathrm{K}_{1 \mathrm{c}}$ showed that dislocation activity increases rapidly close to $\mathrm{K}_{1 \mathrm{c}}\left(\mathrm{K}^{\sim 0} 0.9 \mathrm{~K}_{1 \mathrm{c}}\right)$. There was no evidence for stable crack growth in any specimen at or above $\mathrm{T}_{\mathrm{c}}$.

Specimens deformed above $T_{c}$, fractured at room temperature and then etched, showed evidence for general plasticity over large areas of the specimen.

\section{Interpretation}

\subsection{Nature of plastic zone}

In modelling the stresses from the semielliptical crack, we have assumed that close to the crack the stress field can be approximated by that from a straight edge crack tangent to the crack profile, and that the slip systems activated are controlled by the near crack-tip stress field.

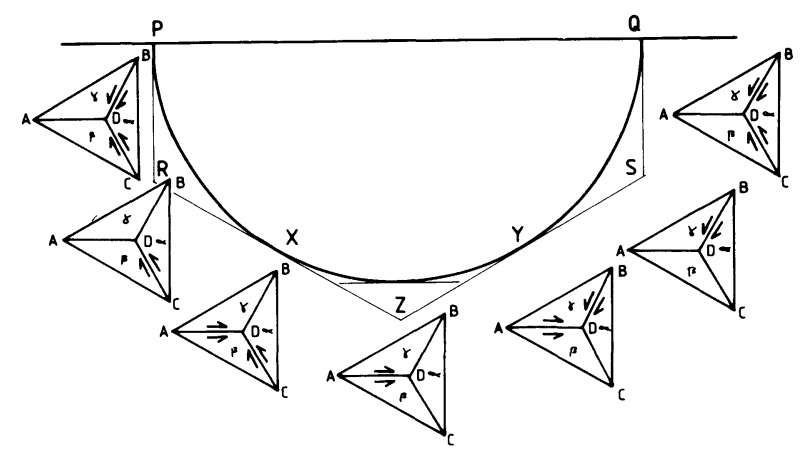

Fig.9: Some of the highly stressed slip systems in regions ahead of the crack with Burgers vectors lying in planes on which dislocations are observed in Fig. 8.

Using the known stress field from an edge crack in plane strain [4] the resolved shear stresses have been calculated and mapped in sections normal to the crack profile for all possible slip systems for orientations of a crack on (111) with its profile parallel to $\langle 112 \overline{\rangle}$ and $\langle 10 \overline{1}\rangle$. Fig.9 shows some of the slip systems with a high resolved shear stress in regions ahead of the crack, indicating also the sense of shear, at different points along the crack 

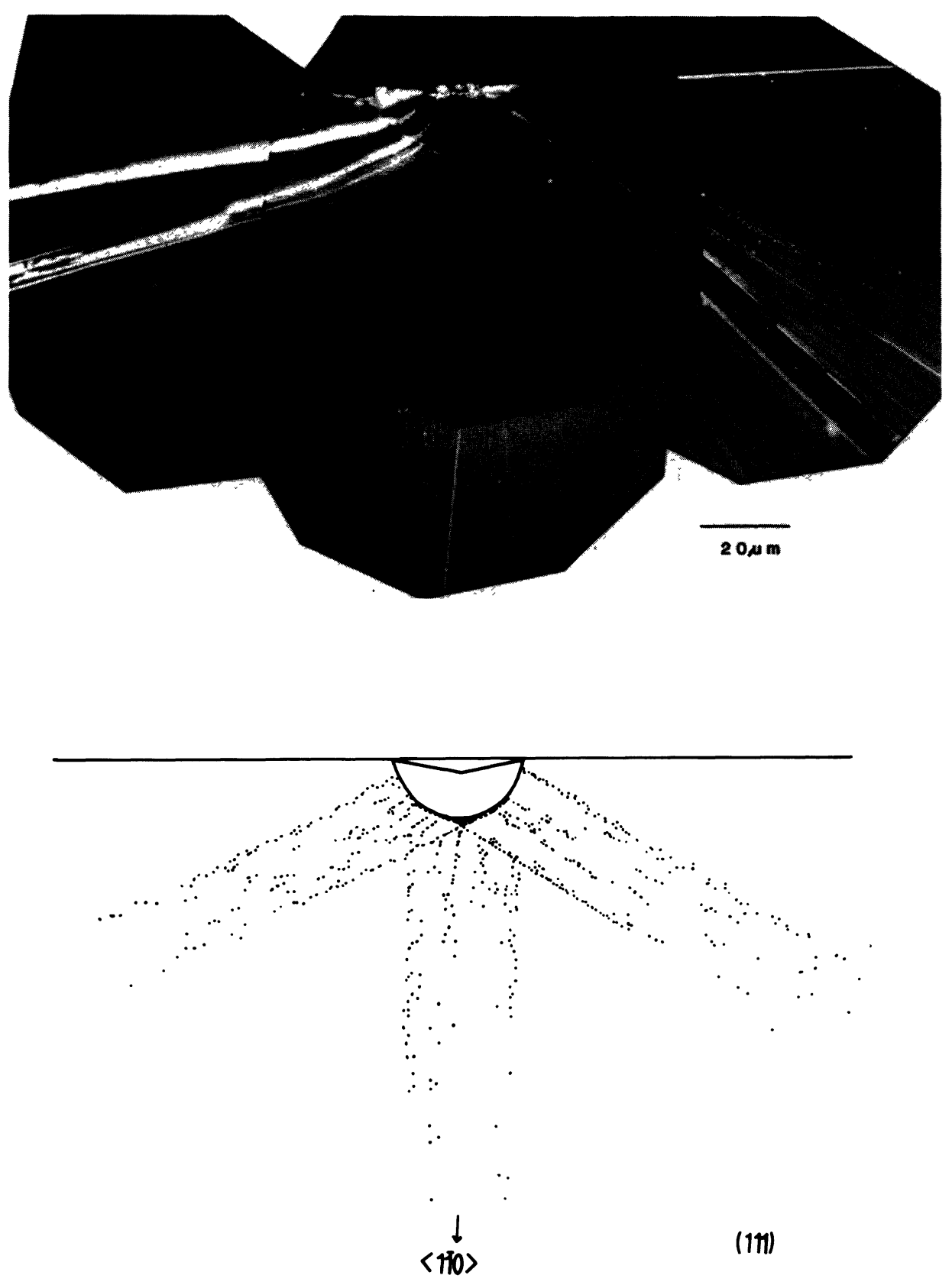

Fig.8(a) Optical micrograph of a specimen deformed at $\mathrm{T}_{\mathrm{c}}$, which failed at $\mathrm{K}=1.6 \mathrm{M} \mathrm{Pa} \mathrm{m} \mathrm{m}^{1 / 2}$, and which was subsequently etched. Rows of dislocations parallel to the traces of (111) glide planes intersecting the crack plane can be seen.

(b) Reproduction of pattern of etch pits in (a) outside the original crack profile. Note that along the two traces tangential to the crack profile making angles of $\pm 30^{\circ}$ with the top surface, there are rows of etch pits only on one side of the tangent point, running into the interior of the crystal. Note also that the rows of etch pits are in the form of inverted pile-ups. 
profile. The Thompson tetrahedron is shown with the apex $D$ above the plane of the diagram. The arrows indicate the directions of shear of material outside the tetrahedron relative to that inside. For simplicity only some of the highest stressed systems are shown. At points $X$ and $Y$ the slip systems tangential to the crack profile, i.e. $\beta$ with Burgers vectors $D A$ and $D C$, and $\boldsymbol{\gamma}$ with Burgers vectors $B D$ and $\mathrm{AD}$ respectively are equally highly stressed. In region $Z$ the two systems $\beta(\underline{A D})$ and $\boldsymbol{\gamma}(\underline{A D})$ are favoured over large areas. We suggest therefore that the dislocation trains observed in Fig. 8 alorg $\mathrm{XZ}$ and $\mathrm{YZ}$ are likely to be on systems $\beta(\underline{\mathrm{AD}})$ and $\gamma(\mathrm{AD})$ respectively, and similarly along $\mathrm{PR}$ and $\mathrm{QS}$ on systems $\alpha(\underline{C D}), \alpha(B D)$ respectively. This prediction needs to be checked by Burgers vector analysis, and TEM experiments are in progress. a

b

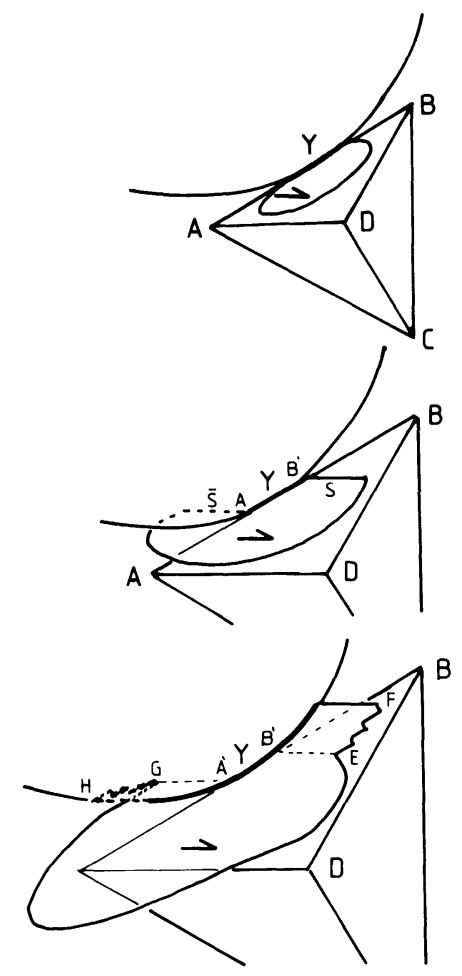

Fig.10: Evolution of a dislocation half loop on $\gamma(\mathrm{AD})$ nucleated at $\mathrm{Y}$ (and shielding the crack), whose ends terminate at the crack tip and which are forced to separate by the stress to follow the crack profile by repeated cross-slip on $\beta$ and $\gamma$, blunting the crack.

Consider now a dislocation loop on system $\gamma($ AD) nucleated at Y. Fig.10 shows how such a loop is likely to develop. As the segment at B approaches the crack plane it will be attracted to it, but when it reaches the screw orientation (see Fig.10b) the sense of the force on the screw will move it to the right, to follow the crack profile approximately by repeated cross-slip on planes $\beta$ and $\gamma$, blunting the crack. The resultant configuration is shown in Fig.10c, where EG is the loop on plane $\gamma$ and EF is a zig-zag edge dislocation lying partly in planes $\beta$ and $\gamma$. It should be noted that, since $E$ is above the plane of the diagram, the loop EG does not intersect the plane of the crack, to the right of $Y$; thus no etch pits will be seen along YB or its extension to the surface, in agreement with observations (Fig.8). On the left hand side of the loop at $A$, the screw has to be below the crack (i.e. below the plane of the diagram) in order for the stresses on it to be in the correct sense for it to follow the crack profile to the left of $Y$ by repeated cross-slip on $\beta$ and $\boldsymbol{\gamma}$. This motion involves shear on $\gamma$ opposite to that shown in Fig.9, and again blunts the crack. The resultant configuration is shown in Fig.10c. The loop on plane $\boldsymbol{\gamma}$ is now below the plane of the diagram at G; it follows that on the left of $Y$ these loops intersect the crack plane and will give rise to etch pits, exactly as observed in Fig. 8.

Finally, it should be noted that if one of the cross-slip segments along $E F$ in Fig.10c is sufficiently long, it can bow out under the crack tip stress on the cross-slip plane into a large loop which will intersect the crack plane, and consequently give rise to etch pits. This mechanism explains the band of etch pits in Fig. 8 along the general direction of the trace of $\mathrm{AC}$, emanating from the region around $\mathrm{Y}$.

Similar considerations apply at points $\mathrm{X}, \mathrm{P}$ and $Q$. Thus it is possible in principle to account for most of the etch pit patterns observed by slip originating from only four sources at points $\mathrm{X}, \mathrm{Y}$, $P, Q$. At this stage the evidence is only circumstantial, albeit consistent with the stress field, and is subject to confirmation by TEM observations.

\subsection{A crack tip shielding model for the DBT}

Fig.10 suggests that the crack is blunted by cross-slip of screws, and that dislocation loops are generated. The stress. field from these loops shields the crack (for review see [4]), so that the local stress intensity factor

$$
\mathrm{K}_{\mathrm{e}}=\mathrm{K}-\Sigma \mathrm{K}_{\mathrm{D}}
$$

where $\Sigma K_{D}$ is the shielding effect from the dislocations, and $K$ is the applied stress intensity factor. Since there is some doubt about the effect of glide on a particular plane on the stress field singularity at the crack tip $[14,15]$, we have modelled the DBT by considering shielding only. As $\mathrm{K}$ increases with time during the test, the criterion for $T_{c}$ is that the shielding must be just sufficient for $\mathrm{K}_{\mathrm{e}}\left\langle\mathrm{K}_{1 \mathrm{c}}\right.$ for all values of $\mathrm{K}$ at all points on the crack profile.

The etch pit patterns suggest that there are only a few effective sources along the crack. In order to make the modelling tractable, the following simplifications are made:

(1) The curved crack with sources at $X, Y, P, Q$ is replaced by a straight crack with two sources, corresponding to $\mathrm{X}$ and $\mathrm{Y}$, say.

(2) Mode I deformation is replaced by mode III deformation. The reason for this is that the dislocation interactions in mode I are much more complicated than for mode III, and although mode III calculations may not give numerically correct estimates, they should give insight to the factors important in the dynamics of the problem. The assumed geometry is shown in Fig.11, with the two sources at $\mathrm{X}$ and $\mathrm{Y}$, and the Burgers vector parallel to the line of the crack. 
crack

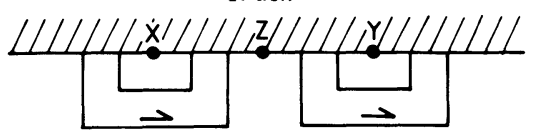

Fig.11: Model used for shielding the crack in mode III. Sources at $X$ and $Y$ emit dislocation loops with Burgers vectors parallel to the line of the crack. Shielding at $\mathrm{Z}$ is assumed to begin when the dislocations have passed $\mathrm{Z}$.

(3) The dislocation interaction is assumed to be that between parallel screws. A line tension term is incorporated which is of the same form as the image term for the screws. Interaction between loops from the different sources is neglected. The edge dislocations are assumed to move with the same velocity as the screws.

Under these conditions the stress on any dislocation at $X_{1}$ is given by

$$
\tau_{X i}=\frac{K}{\left(2 m X_{i}\right)^{1 / 2}}-\alpha \frac{\mu b}{X_{i}}+\frac{\mu b}{2 \pi} \sum_{j} \frac{\left(X_{j} / X_{i}\right)^{1 / 2}}{\left(X_{i}-X_{j}\right)}(5)
$$

where the first term is the crack tip stress, the second the line tension and image stress, and the third term the interaction due to all dislocations at $X_{j}[16,4] ; \mu$ is the shear modulus, and $\alpha$ a constant. Substituting from (1) for the stress in terms of dislocation velocity, we find

$\left(\hat{K} / v_{0}\right)^{1 / m}\left(\mathrm{dX}_{\mathrm{i}} / \mathrm{dK}\right)^{1 / m}=\frac{\mathrm{K}}{\left(2 \pi \mathrm{X}_{\mathrm{i}}\right)^{1 / 2}}-\alpha \frac{\mu \mathrm{b}}{\mathrm{X}_{\mathrm{i}}}+\frac{\mu \mathrm{b}}{2 \pi} \sum_{\mathrm{j}} \frac{\left(\mathrm{X}_{\mathrm{j}} / \mathrm{X}_{\mathrm{i}}\right)^{1 / 2}}{\left(\mathrm{X}_{\mathrm{i}}-\mathrm{X}_{\mathrm{j}}\right)^{1 / 2}}$

We now assume that the dislocation loops at the source can be nucleated and move away from the tip provided the stress at a critical distance $x_{c}$ from the tip is sufficient to expand the loop. Once nucleated the back stress from this dislocation shields the source, and the stress at $x_{c}$ drops below the critical value for loop expansion. As the dislocations move away, the stress at $X_{c}$ increases again and it is assumed that when the critical value is reached, another dislocation is emitted, etc.

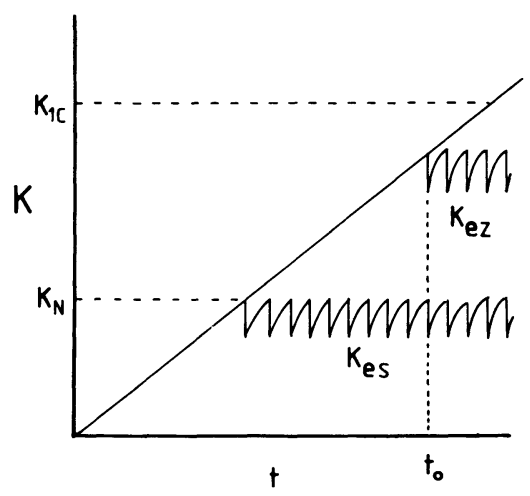

Fig.12: Schematic variation of local stress intensity factors $\mathrm{K}_{\mathrm{es}}$ and $\mathrm{K}_{\mathrm{ez}}$ as a function of time. Dislocations are emitted by the source at $K=K_{N}$, but shielding at $Z$ begins only after time $t_{0}$ when the loops in Fig.11 have passed $\mathrm{Z}$. The material is ductile if $\mathrm{K}_{\mathrm{ez}}<\mathrm{K}_{1 \mathrm{c}}$.
The situation is shown in Fig.12. The condition for nucleation is

$$
\frac{\mathrm{K}}{\left(2 \pi \mathrm{X}_{\mathrm{c}}\right)^{1 / 2}}=\frac{\mu \mathrm{b}}{\mathrm{X}_{\mathrm{c}}}-\frac{\mu \mathrm{b}}{2 \pi \mathrm{j}} \sum \frac{\left(\mathrm{X}_{\mathrm{j}} / \mathrm{X}_{\mathrm{c}}\right)^{1 / 2}}{\left(\mathrm{X}_{\mathrm{c}}-\mathrm{X}_{\mathrm{j}}\right)}
$$

We note that the first dislocation is emitted at a critical

$$
\mathrm{K}=\mathrm{K}_{\mathrm{N}}=\alpha \mu \mathrm{b}\left(2 \pi / \mathrm{X}_{\mathrm{c}}\right)^{1 / 2}
$$

The set of equations (6) can now be solved subject to the boundary condition (7) for various values of $\left(\dot{K} / \mathrm{v}_{0}\right), \alpha$ and $\mathrm{X}_{\mathrm{c}}$ (or equivalently, $\mathrm{K}_{\mathrm{N}}$ ), and the position of each dislocation found at a given $K$. The parameter $m$ is known from dislocation velocity measurements. The local value $\mathrm{K}_{\mathrm{es}}$ at the source (see Fig.12) is given by

$$
K_{e s}=K-\sum_{j}^{\Sigma} \frac{\mu b}{\left(2 \pi X_{j}\right)^{1 / 2}}
$$

On the other hand the point $\mathrm{Z}$ on the crack front (see Fig.11) will be shielded only when the dislocation loops have moved past $Z$. Then the shielding at $\mathrm{Z}$ (see Fig.12) is given by

$$
K_{e z}=K-\sum_{j>j_{0}} \frac{\mu b}{\left(2 \pi x_{j}\right)^{1 / 2}}
$$

summing only over all dislocations which have moved past $Z$. Thus, shielding at $Z$ only starts at a time $t$ o which depends on the distance $X Z$. To determine the values of $T_{c}$ for different, strain rates, we find the critical value of $\left(\dot{K} / v_{0}\right)$ for which $K_{e z}$ never exceeds $K_{1 c}$. If the temperature dependence of $\mathrm{m}$ is neglected, since it is relatively small over a 1 imited temperature range $[11],\left(\dot{\mathrm{K}} / \mathrm{v}_{0}\right)$ is temperature independent provided $\mathrm{K}_{\mathrm{N}}$ is a constant or a function of $\left(\dot{\mathrm{K}} / \mathrm{v}_{\mathrm{o}}\right)$; the observed strain rate dependence of $\mathrm{T}_{c}$ (see equation 3 ) is then explained.

For a value of $K_{N}$ we appeal to experiment. Michot and George [17] report values of $\mathrm{K}_{\mathrm{N}} \sim 0.24$ $\mathrm{M} \mathrm{Pa} \mathrm{m} \mathrm{m}^{1 / 2}$ in the range $800^{\circ}-900 \mathrm{C}$; these values are obtained by keeping the specimens under load for long times at these temperatures, and looking for evidence for slip. Similar values $\left(\sim 0.3 \mathrm{M} \mathrm{Pa} \mathrm{m} \mathrm{m}^{1 / 2}\right)$ have been obtained in the present experiments. With such low values of $\mathrm{K}_{\mathrm{N}}$, the transition is found to be too 'soft'; i.e. although brittle behaviour should be predicted at, say, $50^{\circ} \mathrm{C}$ below $\mathrm{T}_{\mathrm{c}}$, many dislocations should be observed. This is not the case; no plasticity is observed even only a few degrees below $T_{c}$. Furthermore, as reported in Section 2, little dislocation activity actually occurs until $\mathrm{K}$ is close to $\mathrm{K}_{1 \mathrm{c}}$, when sources begin to operate, and rapid multiplication occurs. This suggests a nucleation event for crack tip sources. One possibility is that they are nucleated by existing dislocations, which are attracted to the crack tip, where they transform into sources. Fig.13 shows a possible mechanism; a dislocation $P Q$ moves on $\beta$ from the plastic zone below the indentation to the crack tip; at the tip the screw part of the loop cross-slips on to $\gamma$ and acts as a source, generating the observed dislocation patterns. Once formed at $\mathrm{K}=\mathrm{K}_{0}$, say, such a source could continue to operate at values of $\mathrm{K}_{\mathrm{N}}<\mathrm{K}_{\mathrm{o}}$, producing an avalanche of dislocations. 


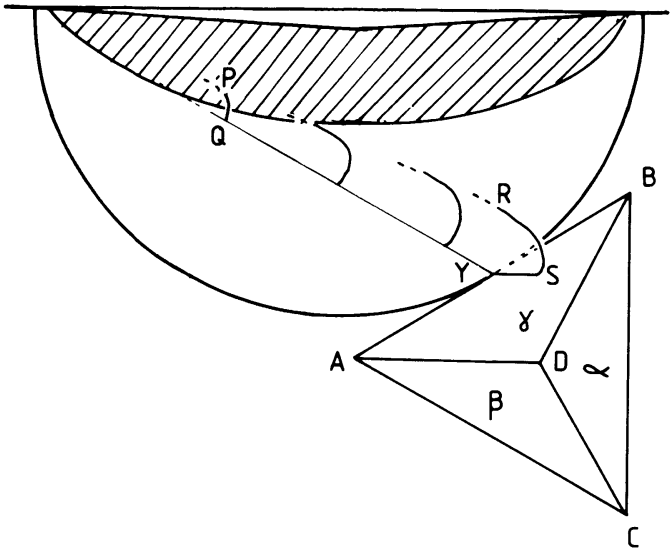

Fig.13: Formation of a crack tip source on $\gamma$ by cross-slip of a dislocation which has moved to the crack tip on $\beta$.
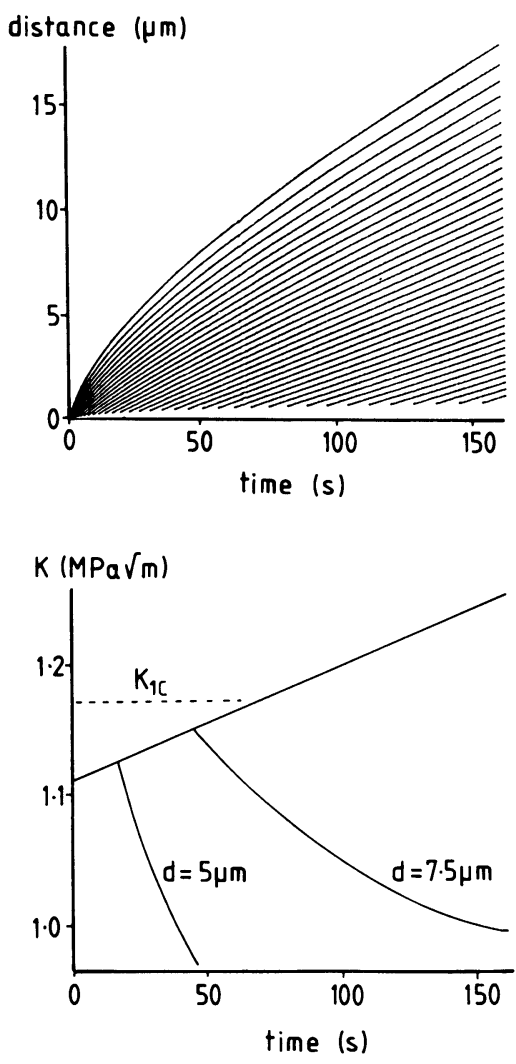

Fig.14: Results of dynamic mode III model calculation, for $\mathrm{T}=550^{\circ} \mathrm{C}, \mathrm{K}=886 \mathrm{~Pa} \mathrm{~m} \mathrm{~m}^{1 / 2} \mathrm{~s}^{-1}$, $\mathrm{K}_{\mathrm{o}}=1.11 \mathrm{M} \mathrm{Pa} \mathrm{m}^{1 / 2}, \mathrm{~K}_{\mathrm{N}}=0.3 \quad \mathrm{M} \quad \mathrm{Pa} \mathrm{m}^{1 / 2}$ ' (a) This shows the position of 200 dislocations as a function of time from when $\mathrm{K}=\mathrm{K}_{\mathrm{o}}$; each curve represents 5 dislocations. At any time the dislocations are in the form of an inverted pile-up. (b) This shows the linear variation of $\mathrm{K}$ with time, and $\mathrm{K}_{\mathrm{e} z}$ for $\mathrm{XZ}=7.5 \mu$ (upper curve) and $X Z=5 \mu$ (lower curve). $K_{e z}<K_{1 c}$ when $\mathrm{K}=\mathrm{K}_{1 \mathrm{c}}$, and the conditions are close to those at the ductile-brittle transition.
Fig.14 shows the results of a calculation for $\mathrm{T}=550^{\circ} \mathrm{C}$ at the strain rate $\dot{\mathrm{K}}$ at which experimentally $\mathrm{T}_{\mathrm{c}} \simeq 550^{\circ} \mathrm{C}$; the values of $\mathrm{K}_{\mathrm{o}}, \mathrm{K}_{\mathrm{N}}$ assumed in the calculation are $\mathrm{K}_{0}=1.11 \mathrm{MPa} \mathrm{m}^{1 / 2^{\mathrm{N}}}$ and $\mathrm{K}_{\mathrm{N}}=0.3 \mathrm{MPa}$ $\mathrm{m}^{1 / 2}$. $\left(\mathrm{K}_{1 \mathrm{c}}\right.$ in the experiments is $\left.=1.17 \mathrm{M} \mathrm{Pa} \mathrm{m}^{1 / 2}.\right)$ Fig. $14 \mathrm{a}$ shows the position of 200 dislocations, grouped together in sets of 5 , as a function of time; they form an inverse pile-up. Fig.14b shows $K$ increasing linearly with time above $\mathrm{K}=\mathrm{K}_{\mathrm{o}}$; the two curves show the variation of $K$ at point $Z$ in Fig.12; the upper curve for $\mathrm{XZ}=7.5 \mu$, corresponding to $\mathrm{XZ}$ in Fig.9 for the small crack size in the experiments, the lower curve for $X Z=5 \mu$. Clearly, $K_{e z}$ drops below $K$ just below $K_{1 c}$, i.e. the calculation is for conditions very close to the DBT. Since the curves $\mathrm{K}_{\mathrm{e}}$ correspond to a particular value of $\left(\mathrm{K} / \mathrm{v}_{0}\right)$, agreement between observed and calculated values of $T_{c}$ for one strain rate, implies agreement at all strain rates, provided $K_{0}$ and $K_{N}$ are constant or functions of $\left(\dot{\mathrm{K}} / \mathrm{v}_{0}\right)$.

Fig.14b also shows that there is a size effect. For smaller values of $\mathrm{XZ}$, with $\mathrm{K}_{\mathrm{o}}, \mathrm{K}_{\mathrm{N}}$ unchanged, $\mathrm{T}_{\mathrm{c}}$ is reduced, and the converse applies to larger values of $\mathrm{XZ}$. This is consistent with the shift to higher temperatures observed for larger crack sizes (see Section 2, Fig.7). However, computations applicable for the actual large crack sizes used in the experiments have yet to be carried out.

It is interesting to compare the predictions of the dynamic model concerning dislocation distributions with experimental observations. The specimen corresponding to Fig. 8 fractured at $550^{\circ} \mathrm{C}$ and $\dot{\mathrm{K}}=886 \mathrm{~Pa} \mathrm{~m} \mathrm{~m}^{1 / 2} \mathrm{~S}^{-1}$ at $\mathrm{K}=1.6 \mathrm{M} \mathrm{Pa} \mathrm{m} \mathrm{m}^{1 / 2}$; the number of dislocations in a given train $\sim 100$, and the leading dislocation travelled $\sim 100 \mu$. The dislocations are arranged in an inverted pile-up, as predicted by the model (see Fig.14a). Extrapolating Fig.14a to fracture suggests that the leading dislocation travels $\sim 50 \mu$, and the number of dislocations is $\sim 300$. Numerical agreement cannot be expected, but the numbers are not unreasonable.

Much remains to be done to make the dynamic model more realistic, to take into account workhardening, to model mode I instead of mode III, to use a more realistic stress field at large distances, etc.

\subsection{Model for $\mathrm{K}_{\mathrm{o}}$}

In sections 3.2 it was suggested that crack tip dislocation sources are generated when existing dislocations reach the crack (see Fig.13). The dislocation velocity (in mode I loading) is given by

$$
\frac{d r}{d t}=-\frac{(K f)^{m}}{(8 \pi r)^{m / 2}} v_{0}
$$

where $f$ is an orientation factor. This can be integrated to give

$$
\overrightarrow{\mathrm{K}}_{\mathrm{K}}=\frac{2(\mathrm{~m}+1)(8 \pi)^{\mathrm{m} / 2} \mathrm{r}_{\mathrm{r}} \mathrm{o}}{(\mathrm{m}+2) \mathrm{f}^{\mathrm{m}}(1+\mathrm{m} / 2)}
$$

where $r_{0}$ is the distance travelled by the dislocation to reach the crack tip, $K_{d}$ is the stress intensity at which the dislocation begins to move. Since $K_{0}$ is close to $K_{1 c}, K_{d}$ is likely to be negligible; $r_{0}$ can be taken as the crack radius in the present experiments. It is clear at once that $\mathrm{K}$ is only a function of $\left(\mathrm{v}_{0} / \dot{\mathrm{K}}\right)$; thus the assumption made in the dynamic pile-up computations in Section 3.2 that $K_{0}$ is constant for a given value of $\left(\mathrm{K} / \mathrm{v}_{0}\right)$ is consistent with the proposed model for $\mathrm{K}_{0}$. 
Thus, the condition for $T_{c}$ is that dislocation sources at the crack tip must be formed by glide of existing dislocations just in time for the sources to emit sufficient dislocations to shield the most vulnerable part of the crack (i.e. furthest away from the sources) before $K$ reaches $K_{1 c}$, and such that $K_{e z}\left\langle K_{1 c}\right.$ even as $K$ rises further.

Since $\mathrm{K}_{\mathrm{o}} \sim \mathrm{K}_{1 \mathrm{c}}$, equation 12 can be used to derive an approximate value for $\mathrm{T}_{\mathrm{c}}$; i.e.

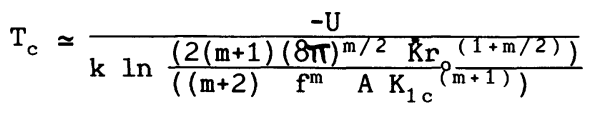

All parameters in (13) are known or can be estimated. For $m=1, f=1 / 4$, table 2 shows the results for $\dot{K}=886 / \mathrm{Pa} \mathrm{m} \mathrm{m}^{1 / 2} \mathrm{~s}^{-1}$ for two crack sizes.

$\underline{\text { Table } 2}$

\section{Transition Temperature}

\begin{tabular}{ccc}
$r_{0}$ & Model ${ }^{\circ} \mathrm{C}$ & Experiment ${ }^{\circ} \mathrm{C}$ \\
\hline $10 \mu$ & $\sim 575$ & 550 \\
$30 \mu$ & $\sim 640$ & 600
\end{tabular}

The agreement between the model predictions and experiment is reasonable, and the observed size effect is explained. As mentioned in Section 3.2, a size effect is predicted (in the same sense) from the dynamic pile-up calculations; if the temperature shift predicted from these calculations differs from that made from equation 13, an adjustment to $\mathrm{K}_{\mathrm{o}}$ may be required; this is likely to be small.

This model for $\mathrm{K}_{\mathrm{o}}$ predicts that the transition should be very sharp; i.e. for a given value of $r_{0}$, no plasticity would be observed for temperatures less than about $2^{\circ} \mathrm{C}$ below $\mathrm{T}_{\mathrm{c}}$. The spread in values of $\mathrm{T}_{c}$ from specimen to specimen $\left(\sim 5^{\circ} \mathrm{C}\right)$ would be due to variations in $r_{0}$.

\subsection{Comparison with other work}

The experiments of St. John [6], Brede [13] and Michot and George [17] have all been carried out for straight cracks in a wedge type, constant $K$, specimen geometry. The values of $\mathrm{T}$ are about $100^{\circ} \mathrm{C}$ above those in the present experiments for similar values of $\dot{\mathrm{K}}$. A possible explanation is that the density of accessible bulk dislocation sources is much smaller than in the present specimens, in which a plastic zone is introduced by indentation at the surface. $\mathrm{T}$ (St. John) is explained using equation 13 , if $r_{0} \sim 60 \mu$ assuming the same activation energy $U$ for the Oxford and St. John results, or $r \quad \sim 450 \mu$ for $\mathrm{U}=2.1$ and $1.9 \mathrm{ev}$ respectively (see Table 1 ). The former value of $r_{0}$ corresponds to a volume density of sources $\sim 10^{6} \mathrm{~cm}^{-3}$; Michot and George [17] refer to the existence of such source densities (swirl defects?) in their crystals; the latter value suggests operation of surface sources in St. John's experiments (specimen thickness $\sim 1 \mathrm{~mm}$ ).

The question arises whether in the experiments of St. John and other workers, the density of bulk sources is so low that homogeneous nucleation at the crack tip occurs as suggested originally by Rice and Thomson [2]. This is unlikely for the following reasons. Both St. John [6] and Brede [13] find that $T_{c}$ is controlled by dislocation velocity. The dynamic pile-up calculations show that this is only true if $K_{N}$ itself is constant or a function only of $\left(\dot{K} / \mathrm{v}_{\mathrm{o}}\right)$. Thus, the experiments suggest that $\mathrm{K}_{\mathrm{N}}$ is not determined by a thermally activated process for dislocation nucleation with an activation energy different from that for dislocation velocity. We therefore conclude that even in these 'dislocation-free' crystals of Si crack tip plasticity occurs by promoting dislocation motion from sources or potential sources in the crystal, to the crack tip where new sources can be generated.

Michot and George [17] have carried out extensive Burgers vector analysis by $X$-ray topography of dislocations in the plastic zone in their specimens. For straight cracks whose profiles are parallel to $X Z$, or $X Y$ in Fig.9, they find that systems intersecting the cracks are those which are mainly activated, and that in the $\mathrm{XZ}$ orientation relatively few dislocations are generated on the slip system tangent to the crack. Their observations on slip planes for the XY orientation are consistent with our etch pit observations, but in the $\mathrm{XZ}$ (or $\mathrm{YZ}$ ) orientation there is clear evidence in the present experiments for high activity on the slip systems tangent to the crack. This discrepancy is not understood.

Michot and George [17] also find much activity with Burgers vectors parallel to the crack plane. This slip may be in response to the mode III component induced locally; for example in Fig.9, slip with Burgers vector $A D$ in region $Z$, induces a mode III component which can be relieved by slip with $A B$, and $A C$. In region $X$, slip with $C D$, would induce locally both a mode III and mode II component, leading to the generation of several other slip systems. Clearly the expected dislocation activity is complex, and needs further elucidation.

\section{Conclusions}

Although much further work needs to be done to determine the dislocation distributions in the present experiments, and the dynamic modelling has to be further developed, a number of tentative conclusions can now be drawn; the following list should be considered in this way.

\subsection{Silicon}

(1) The plastic zone around crack tips in $\mathrm{Si}$ is formed by dislocations in the bulk crystal moving to the crack and forming crack tip sources which generate shielding and blunting dislocations.

(2) Blunting can occur by screw dislocations on slip systems intersecting the crack profile cross-slipping along it.

(3) The DBT occurs when the rate of shielding produced by dislocations from sources at or near particular sites at the crack tip is sufficiently fast at the most vulnerable points along the crack, away from the sources, so that $\mathrm{K}_{\mathrm{e}}\left\langle\mathrm{K}_{1 \mathrm{c}}\right.$ for all values of $\mathrm{K}$.

(4) $T_{c}$ is controlled mainly by the time taken for existing dislocations to reach the crack tip, i.e. by the dislocation velocity, and the distance of the dislocation from the crack tip.

(5) The strain-rate dependence of $T_{c}$ is determined by the activation energy for dislocation velocity. 
(6) $T_{c}$ is lowered by an increase in dislocation density.

\subsection{General}

(7) Although, as pointed out by Lin and Thomson [10], collision between dislocations and crack tips are relatively rare events when viewed on an atomic scale, such collision can lead to very efficient crack shielding and blunting, by the formation of crack tip sources, and by cross-slip of screws.

(8) Whether in any real intrinsically brittle material nucleation at the crack tip is ratecontrolling must depend on the relative values of the activation energy for nucleation and of the velocity of dislocations, and on the dislocation density. The operation of a bulk source at the crack tip should be easier than the repeated nucleation of dislocation loops at the tip. Hence, materials with existing dislocations should be more ductile than dislocation free material. In many real intrinsically brittle materials it seems likely that crack tip plasticity will occur by mechanisms initiated by existing dislocations.

(9) Provided crack tip plasticity is controlled by dislocation velocity, mechanisms which impede dislocation motion, e.g. neutron irradiation, solution or precipitation hardening, which raise the yield stress, will also increase $T_{c}$. Increasing the dislocation density lowers $T_{C}$, until work-hardening becomes important (Ashby and Embury [9]).

(10) If crack tip plasticity is controlled by existing dislocations, and if the temperature and stress dependence of dislocation velocity and the dislocation density are known, $T_{c}$ can be estimated from equation 13 .

\section{Acknowledgement}

We would like to thank Professor P. Pirouz for help in the initial stages of the experiments, and the Venture Research Unit of B.P. and SERC for financial support.

\section{References}

1. Kelly, A., Tyson, W. and Cottrell, A. Phil.Mag. 15 (1967 567.

2. Rice, J.R. and Thomson, R., Phil.Mag. 29 (1974) 73

3. Haasen, P., in: Atomistics of Fracture, eds. R. Latanision and J. Pickens (New York, Plenum) 1983, p.707.

4. Thomson, R., in: Solid State Physics, eds. H. Ehrenreich and D. Turnbull (New York, Academic Press) 1986, Vol.39, p.1.

5. Argon, A.S., Acta Metall. 35 (1987) 185

6. St. John, C., Phil.Mag. 32 (1975) 1193.

7. Ohr, S.M., Materials Science and Engineering 72 (1985) 1.

8. Burns, S.J. and Webb, W.W., Trans.Met.Soc. A.I.M.E. 236 (1966) 1165.

9. Ashby, M.F. and Embury, J.D., Scripta Metall. 19 (1985) 557.

10. Lin, I-H. and Thomson, R., Scripta Metall. 20 (1986) 1367.

11. George, A. and Champier, G., Phys.Stat.Solidi (a) 53 (1979) 529

12. Hirsch, P.B., in: Dislocations and Properties of Real Materials, eds. M.H. Loretto (London, Institute of Metals) 1985, p.333.

13. Brede, M., Ph.D. thesis, University of Gottingen, 1986

14. Sinclair, J.E., in: Fundamentals of Deformation and Fracture, eds. B.A. Bilby, K.J. Miller, and J.R. Willis (Cambridge, University Press) 1985, p.628.

15. Paskin, A., Massoumzadeh, B., Shukla, K., Sieradzki, K. and Dienes, G.J., Acta Metall. 33 (1985) 1987.

16. Majumdar, B.S. and Burns, S.J., Acta Metall. 29 (1981) 579.

17. Michot, G. and George, A., Scripta Metall. 20 (1986) 1495 